\title{
A new spectrophotometric method for determination of residual polydiallyldimethylammonium chloride flocculant in treated water based on a diazotization-coupled ion pair
}

\author{
Isaac W Mwangi ${ }^{1}$, J Catherine Ngila1* and Patrick Ndungu ${ }^{2}$ \\ ${ }^{1}$ Department of Chemical Technology, University of Johannesburg, Doornfontein Campus, PO Box 17011, Doornfontein 2028, \\ Johannesburg, South Africa \\ ${ }^{2}$ School of Chemistry, University of KwaZulu-Natal, P/Bag X45001, Westville Durban 4000, South Africa
}

\begin{abstract}
Polydiallyldimethylammonium chloride (polyDADMAC) is a water-soluble cationic polyelectrolyte used for water treatment. Its residues in treated water are contaminants as they react with chlorine to produce a carcinogenic compound. Commonly-used techniques for quantification of the polycation, such as colloidal and potentiometric titration as well as ${ }^{1} \mathrm{H}$ NMR, have poor sensitivity and detection limits. This paper describes a more sensitive UV spectrophotometric method for quantitative determination of residual polyDADMAC in treated water, through formation of an ion pair with (4-hydroxy1-napthylazo) benzene-sulphonic acid (dye). The ion pair, which is a colloidal solid material, was characterised by FTIR, ${ }^{13} \mathrm{C}$ NMR and ${ }^{1} \mathrm{H}$ NMR techniques. The colloid materials formed with different concentrations of polyDADMAC were dissolved in either N,N-dimethylformamide or 1,4-dioxane, followed by determination with UV spectrophotometry. The wavelength of maximum absorption $\left(\lambda_{\max }\right)$ was found to be dependent on the solvent used, with 1,4-dioxane showing a better linear range of $0.1-1.8 \mathrm{mg} \cdot \ell^{-1}$ polyDADMAC. Varying the $\mathrm{pH}$ of the solutions had no significant effect on $\lambda_{\max }$.
\end{abstract}

Keywords: Polydiallyldimethylammonium chloride, flocculant, UV spectrophotometry, (4-hydroxy-1-napthylazo) benzene-sulphonic acid, treated water

\section{Introduction}

Domestic water is normally abstracted from rivers, dams and groundwater, in its raw state, and contains a substantial amount of suspended matter. It therefore must undergo treatment that will render it suitable for human consumption. The initial stage (clarification) involves the use of coagulants and flocculants which accelerate the settling of suspended particles. Organic cationic polyelectrolytes for the water treatment process are currently preferred over inorganic flocculants due to advantages in clarification of suspended particles. Examples of the most frequently applied flocculants are polydiallylydimethyl ammonium chloride (polyDADMAC) and epichlorohydrindimethylamine (epi-DMA), which are used in $75 \%$ of waterworks in South Africa (Majam et. al., 2004). The advantages of organic cationic polyelectrolytes over inorganic coagulants include an increase in the solid-liquid separation rate, a smaller sludge volume, non $\mathrm{pH}$-dependence and low levels of dissolved salts in the final treated water. These quaternary ammonium polyelectrolytes have been found to solve the problem of slowsettling flocs in low-temperature coagulation and in the treatment of soft coloured waters, by improving settling of particles (Faust, 1983). The mechanism of water treatment is by inducing aggregation of molecules with opposite charges to form a new combination product containing colloidal particles (Mocchiutti and Zanuttini, 2007).

\footnotetext{
* To whom all correspondence should be addressed.

용 +2711 5596196 / +27 71632 0106; fax: +27 11 559-6425; e-mail: icngila2002@yahoo.com

Received 22 December 2011; accepted in revised form 5 October 2012.
}

Quaternary ammonium cations are permanently charged (Xia et. al., 2007), and when they interact with the environment while in active form (charged) they continue to form free primary radicals which are difficult to terminate (Assem et. al., 2007). Such free radicals initiate reactions that can form undesirable compounds. For instance, it has been realised from recent studies that organic cations react with chlorine to form $N$-nitrosodimethylamine (NDMA) during the chlorine water-disinfection process (Park et. al., 2009). NDMA is a human carcinogen which has been identified as a by-product of disinfection of water containing trace levels of polyDADMAC (Park et. al., 2009). There is therefore a need to determine the concentration of the polyelectrolyte cations that pass through the flocculation stage, before the chlorination process, with a view to ascertaining the safety of water to consumers. In addition, it is necessary to routinely monitor residual levels of polyDADMAC in the final treated water so as to advise on its removal.

It should be noted that polyDADMAC, like any other polyelectrolyte, when dissolved in water dissociates to form simple units of varying monomeric sizes (Gennes, 1979). The dissociated repeating units bear an electrolyte group, making the polymers charged, and, hence, vulnerable to further reaction. These properties of polyelectrolytes are thus similar to those of ionic salts, which gives rise to their being termed polysalts (Gennes, 1979).

Available methods for determining the concentrations of polyelectrolytes are unsatisfactory because polyelectrolytes have high detection limits and are therefore not suitable for trace-level analysis. For instance a detection limit of 10-40 $\mathrm{mg} \cdot \ell^{-1}$ was reported by Becker et. al. (2004), who estimated the level of polyDADMAC in water by fluorescent tagging. Other methods are based on indirect titration methods or back 
titration techniques (Wanga et. al., 1989). These methods have severe limitations in terms of achieving good linearity, accuracy, precision, reproducibility and detection limits (Sakai., 2001). The other challenge is that the cationic polymer is UV inactive and it is therefore not possible to employ UV-Vis spectrophotometry for its analysis (John et. al., 2002). However, a study by Parazak et. al. (1987) observed that complexation of the polyelectrolyte with an anionic dye forms an insoluble complex. Studies have been undertaken to determine the correlation between charge density and antimicrobial efficacy for quantification of quaternary ammonium salts attached on a surface, by Tiller et. al. (2001), Al-Shihry (2005), Kügler et. al. (2005) and Zander et. al. (2008), which showed that dyes bind to quaternary ammonium at a molar ratio of $1: 1$.

In view of the challenges faced in the determination of polyDADMAC levels in water, the study reported herein exploited the solubility property of the polyDADMAC-dye ion pair formed when polyDADMAC is reacted with (4-hydroxy1-naphylazo) benzene-sulphonic acid dye. The ion pair (complex) is a coloured colloid which is soluble in selected non-aqueous solvents. The quantity of the ion pair in the nonaqueous solution was then determined by UV spectrophotometry. This approach was used to develop an efficient new method for the determination of trace levels of polyDADMAC residuals in treated water.

\section{Materials and methods}

\section{Chemicals and reagents}

All of the solutions were prepared in double-distilled water. The reagents used were of analytical grade. Sodium nitrite, sodium hydroxide and sodium bicarbonate were supplied by Associated Chemical Supplies Ltd, Fluka Analytical (Buchs, Switzerland). Sulphanilic acid, N,N-dimethylformamide (DMF), 1,4-dioxane and 1-naphthol were supplied by BDH (London, UK) while hydrochloric acid and deuterated water were supplied by Sigma Aldrich (Johannesburg, South Africa). The polyDADMAC was supplied by Umgeni Water Treatment Works (Durban, South Africa), and had a density of $1.09 \mathrm{~g} \cdot \mathrm{m} \ell^{-1}$ and $35 \% \mathrm{w} / \mathrm{v}$ solution in water (diallyldimethyl ammonium chloride, DADMAC monomer has a molecular mass 161.66 $\left.\mathrm{g} \cdot \mathrm{mol}^{-1}\right)$.

\section{Instrumentation}

Fourier transform infrared (FT-IR) spectrophotometer, Perkin Elmer 100 (USA) with sampling accessory, was used to characterise the polyDADMAC-dye ion pair (Mukamel, 2000). ${ }^{1} \mathrm{H}$ NMR spectrometry was performed with a $400 \mathrm{MHz}$ Bruker Avance spectrometer (Germany) using deuterium oxide as the lock solvent. Solid samples of the ion pair were characterised by solid-state carbon-13 nuclear magnetic resonance, ${ }^{13} \mathrm{C}$ NMR, using a Bruker 600 spectrometer with cross polarisation/magic angle spinning (CP/MAS). The ${ }^{13} \mathrm{C}$ NMR experiments were performed at a frequency of $10 \mathrm{MHz}$ while cross-polarisation was calibrated with glycine at $10 \mathrm{KHz}$ and spinning rate was set at $5 \mathrm{KHz}$. The contact time for $\mathrm{CP} / \mathrm{MAS}$ was $1 \mathrm{~ms}$ and the delay time for acquisition was $5 \mathrm{~s}$. Optical absorbance measurements were carried out on a Perkin Elmer LAMBDA 35 UV-Vis spectrophotometer (USA). The analysis was carried out using a wavelength range between 300 and $200 \mathrm{~nm}$.

\section{Experimental procedures}

Preparation of azo dye and polyelectrolyte ion pair

\section{Diazotization of sulphanilic acid}

A $6 \mathrm{mM}$ solution of diazosulphanilic acid was prepared by dissolving $0.116 \mathrm{~g}$ of sulphanilic acid and $0.035 \mathrm{~g}$ sodium nitrite in approximately $500 \mathrm{~m} \ell$ of water. The solution was cooled to $0^{\circ} \mathrm{C}$ on ice, and $2 \mathrm{~m} \ell$ of $2 \mathrm{M} \mathrm{HC} 1$ was added with vigorous stirring. The presence of excess nitrous acid was tested using a starch-iodide paper and the excess nitrous acid mopped up with a few drops of sulphanilic acid solution (Schoutissen, 1933).

\section{The coupling reaction of the azo dye and naphthol} The solution (about $500 \mathrm{~m} \ell$ ) of azo dye prepared above was reacted with 1-naphthol $(0.0067 \mathrm{~mol})$ coupling reagent solution. The latter was prepared by dissolving $0.969 \mathrm{~g}$ of 1-naphthol (molar mass of $144.17 \mathrm{~g} \cdot \mathrm{mol}^{-1}$ ) in a minimum amount of ethanol $(10 \mathrm{~m} \ell)$ followed by addition of $20 \mathrm{~m} \ell$ of $0.1 \mathrm{~mol} \cdot \ell^{-1}$ sodium bicarbonate (Whitlock et. al., 1972). Finally $500 \mathrm{~m} \ell$ of azo dye was added. The solution mixture was made up to $1 \ell$ with cold distilled water $\left(5^{\circ} \mathrm{C}\right)$ and stored under dark conditions (Whitlock et. al., 1972). The coupled product, (4-hydroxy-1-napthylazo) benzene-sulphonic acid, has a molecular mass of $350.33 \mathrm{~g} \cdot \mathrm{mol}^{-1}$, and is highly water-soluble (Horita et. al., 1997).

\section{Formation of polyDADMAC-dye ion pair}

Composite diazotization-coupling reagent containing sulphanilic acid as the diazotisable aromatic amine and 1-naphthol as the coupling agent was used for the spectrophotometric determination of trace amounts of polyDADMAC. The coupled azo dye $(5 \mathrm{~m} \ell)$ was reacted with several portions $(1 \ell)$ of varying concentrations $\left(0.1-25 \mathrm{mg} \cdot \ell^{-1}\right)$ of polyDADMAC and the mixture was allowed to equilibrate for $2 \mathrm{~h}$ resulting in the formation of a colloid (Horita et. al., 1997).

\section{Characterisation experiments}

The polyDADMAC-dye ion pair colloid was filtered through a sintered glass crucible (number 4, porosity specification) and the resulting solid mass dissolved in either $10 \mathrm{~m} \ell$ of dimethylformamide (DMF) or 1,4-dioxane, separately (Horita et. al., 1997). The solutions were diluted to $1 \ell$ and then analysed using a UV-Vis spectrophotometer. Each respective blank reference solution for this analysis was prepared by dissolving $10 \mathrm{~m} \ell$ of either DMF or 1,4-dioxane and diluting the resultant solution to $1 \ell$ with water, similarly to the samples.

Samples for FTIR and ${ }^{13} \mathrm{CNMR}$ analyses were prepared by reacting solutions of known polyDADMAC concentration with the coupled dye. The resulting mixture was filtered through a sintered glass crucible. The residual solid colloidal material was dried at $60^{\circ} \mathrm{C}$ and cooled in a desiccator before analysis. Samples for characterisation experiments with ${ }^{1} \mathrm{HNMR}$ were prepared by measuring $9 \mu \ell$ of polyDADMAC $\left(1.09 \mathrm{~g} \cdot \ell^{-1}, 35 \%\right.$ solution in water) into a vial and diluting this with $1 \mathrm{~m} \ell$ of deuterated water. Solutions for characterisation with UV-Vis spectrophotometry were prepared by reacting known volumes of dye solutions with known quantities of polyDADMAC and allowing the mixtures enough time to form colloids. The products were filtered through a sintered glass crucible and the resulting solid dissolved in either dimethylformamide or 1,4-dioxane. 


\section{Spectrophotometric determination of trace amounts of polyDADMAC}

Experiments to quantify polyDADMAC by ${ }^{1} \mathrm{H}$ NMR technique were done by preparing the polyelectrolyte solution in deuterated water. Approximately $10 \mathrm{mg}$ of polyDADMAC was placed in a vial and $1 \mathrm{~m} \ell$ of deuterated water was added. A series of dilutions with deuterated water were performed to obtain varying concentrations of the analyte. These solutions were transferred to clean dry NMR sample tubes and filled to a 5-cm length of the tube. The sample tubes were then introduced into the $400 \mathrm{MHz}$ Bruker Avance spectrometer for analysis.

Quantification of polyDADMAC by UV-Vis spectrophotometric technique was done by adding $5 \mathrm{~m} \ell$ of coupled azo dye to $1 \ell$ of varying concentrations $\left(0.1-25 \mathrm{mg} \cdot \ell^{-1}\right)$ of polyDADMAC solution to form a colloidal material. The colloid was filtered through a sintered glass crucible (number 4, porosity specification) and the resulting solid mass dissolved in $10 \mathrm{~m} \ell$ of either dimethylformamide (DMF) or 1,4-dioxane. The resulting mixture was quantified on a UV-Vis spectrophotometer. Calibration curves for solutions prepared in both 1,4-dioxane and DMF were obtained for the determination of the content of the polyelectrolyte in water.

Water samples (4 samples of $3 \ell$ each) were collected in polyethylene bottles on different dates (August 2010) from the Umgeni River in Durban. The samples were filtered through a sintered glass crucible and treated with polyDADMAC, immediately after collection. A similar procedure (as used for standards) was performed for the treatment of water samples where a volume of $5 \mathrm{~m} \ell$ of azo dye was reacted with $1.0 \ell$ of the sample water. This was followed by filtration through the sintered glass crucible after equilibration, so as to obtain the solid ion pair for UV spectrophotometric analysis.

\section{Results and discussion}

\section{PolyDADMAC-dye ion pair formation}

The diazotization process, diazo-coupling and ion pair formation is presented in Scheme 1 (Schoutissen, 1933).

The ion pair formed was a dark red coloured solution due to the presence of azo dye. Several experiments were carried out to investigate the properties of the ion pair and the results are given in the respective sections. The ion pair has a molecular weight of $511.99 \mathrm{~g} \cdot \mathrm{mol}^{-1}$ (Horita et.al., 1997).
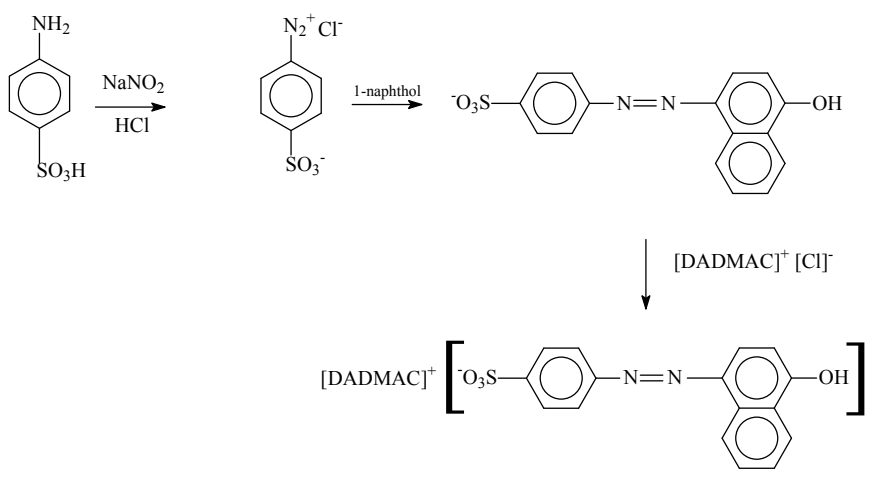

Scheme 1

Diazotization process, coupling reaction and formation of polyDADMAC-dye ion pair

\section{Characterisation of the polyDADMAC-dye ion pair}

The ion pair was characterised by UV-Vis, FTIR, ${ }^{13} \mathrm{C}$ NMR and ${ }^{1} \mathrm{H}$ NMR techniques. These methods provide information about the composition and functional groups, as well as the structure of the ion pair.

\section{FTIR characterisation}

The FTIR-characterisation of polyDADMAC alone, and of the polyDADMAC-dye ion pair, resulted in the spectra shown in Fig. 1.

The spectra in Fig. 1 show the presence of functional groups found in both the dye and polyDADMAC. A band at $3355.76 \mathrm{~cm}^{-1}$ was observed which was assigned to aliphatic secondary amines (Coates, 2000). The band at $1135.29 \mathrm{~cm}^{-1}$ was assigned to the $\mathrm{C}-\mathrm{N}$ stretch of a secondary amine (Yang et. al., 1996; Khazaei et. al., 2007 ), whereas the band at 1 $215.87 \mathrm{~cm}^{-1}$ was assigned to the organic sulphates. The organic sulphate band was absent in the spectrum of polyDADMAC but appears in the ion-pair spectrum due to the presence of the dye (Khazaei et. al., 2007 ). The band at $2938.55 \mathrm{~cm}^{-1}$ was assigned to $\mathrm{C}-\mathrm{H}$ of the aromatic ring from the dye and the band at $1631.11 \mathrm{~cm}^{-1}$ is characteristic of $\mathrm{C}-\mathrm{H}$ in the conjugation of an aromatic ring. The latter confirms the presence of a delocalised $\pi$ electron system of an aromatic ring (Khazaei et. al., 2007 ). The signal at $1635.24 \mathrm{~cm}^{-1}$ in (B) was also assigned to $\mathrm{C}-\mathrm{H}$ stretch in the polyelectrolyte (Khazaei et. al., 2007). The observed shoulder at $1631.11 \mathrm{~cm}^{-1}$ in Fig. 1(A), arises from

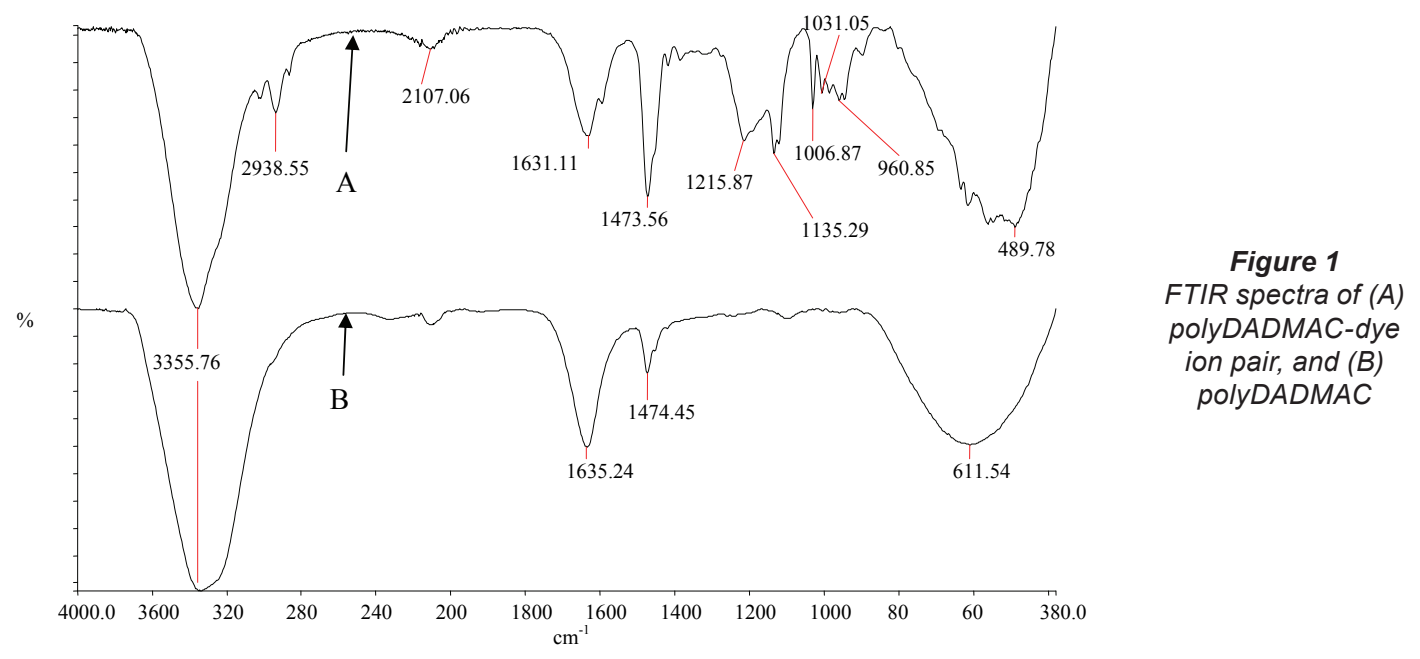




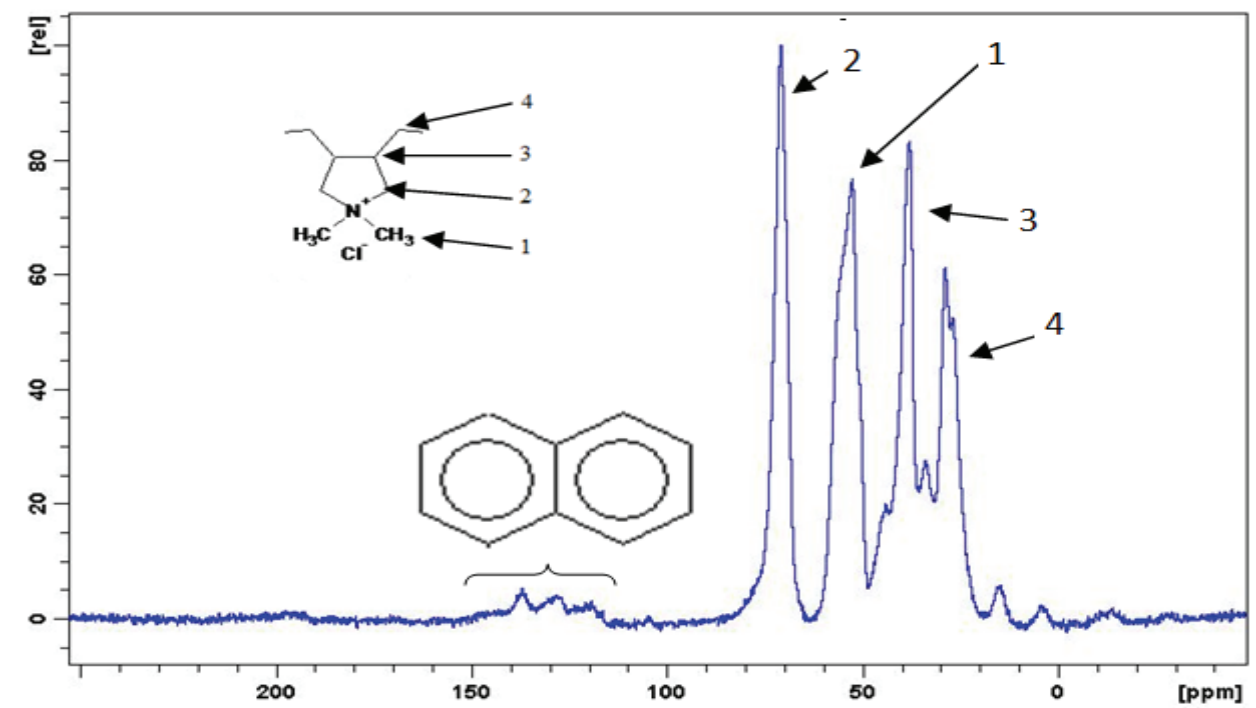

Figure 2

CP/MAS ${ }^{13} \mathrm{C}$ NMR spectrum of $D A D M A C$-dye ion pair: Inset structure - Numbers 1, 2, 3, 4 in the signals correspond to the respective carbon atom

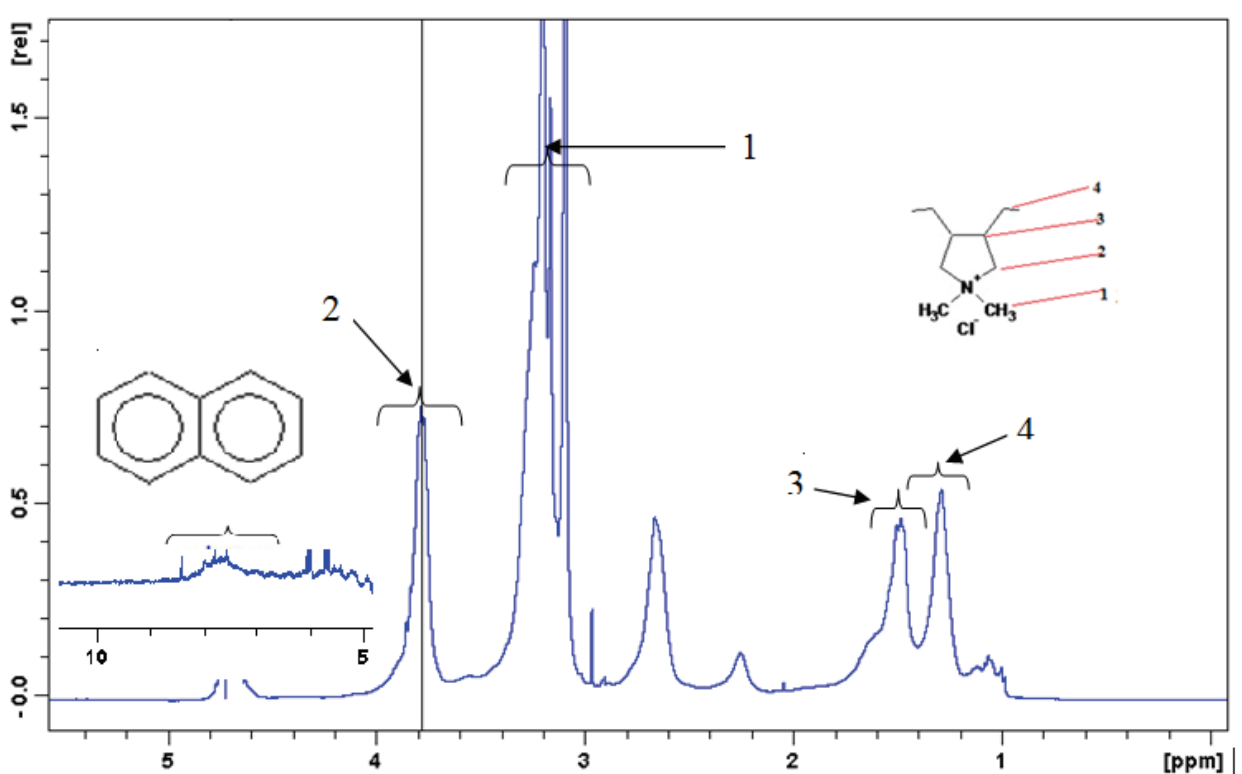

Figure 3

${ }^{1} \mathrm{H}$ NMR spectrum of polyDADMAC-dye ion pair: Inset structure -Numbers 1, 2, 3,4 in the signals correspond to the respective proton environments in the structure shown

substituents on the ring as observed by Coates (2000). The band at $1473.56 \mathrm{~cm}^{-1}$, appearing on both spectra, indicates a long carbon chain with a high degree of regularity for the linear backbone structure (Xamena et. al., 2004). This is possibly contributed by the polyDADMAC polyelectrolyte. It was observed that the signal intensity was enhanced upon the formation of the ion pair as compared to the polyelectrolyte alone, shown in Fig. 1(B), confirming formation of an ion pair. The increased signal intensity (Fig. 1(A)) may be a result of signal amplification due to the functional groups from both molecules of the ion pair.

\section{Characterisation by CP/MAS ${ }^{13} \mathrm{C} N M R$ and ${ }^{1} \mathrm{C}$ NMR}

A solid sample of polyDADMAC-dye ion pair was characterised by $\mathrm{CP} / \mathrm{MAS}{ }^{13} \mathrm{C}$ NMR. The results are given in Fig. 2 .

From the spectrum (Fig. 2), the assignment of the peak of the ion pair corresponds to a linear polymer with 5 -membered pyrollidinium ring. This peak assignment was identical to that described by Lancaster et. al (1976) and later confirmed by Assem et al. (2007) when using a trithiocarbonate RAFT (Reversible Addition Fragmentation Chain Transfer) agent. Signals (Fig. 2) contributed by the dye were observed at 127.4 $\delta$ and $138.3 \delta$ but were very small owing to poor sensitivity of the technique. A sample solution of the polyDADMAC-dye solid ion pair previously analysed with $\mathrm{CP} / \mathrm{MAS}{ }^{13} \mathrm{C}$ NMR was prepared in deuterated water and also analysed with ${ }^{1} \mathrm{H}$ NMR. The results are given in Fig. 3.

The ${ }^{1} \mathrm{H}$ NMR spectrum of the polyDADMAC-dye ion pair showed peaks due to both the polyDADMAC and the dye. However, the peaks due to the aromatic hydrogen atoms from the dye were not easily observable because of the poor sensitivity of the method. This required one to perform repeated scanning to enable visualisation of the poorly-resolved tiny signals. The aromatic hydrogen atoms were observed in the range $7.5-8.0 \delta$ (see Fig. 3 inset, between $4 \delta$ and $5 \delta$ ). By contrast, the hydrogen peaks in polyDADMAC, unlike those from the dye, were clearly detected on the ${ }^{1} \mathrm{H}$ NMR spectrum as shown in Fig. 4, which is similar to studies reported by Saveyna et. al. (2008). For the purpose of quantification, the band at $3.7 \delta$ was considered and its intensity monitored at varying concentrations of polyDADMAC solutions in deuterated water.

Figure 4 shows an example of one of the results obtained when the concentration of the polyelectrolyte was $1.0 \mathrm{mg} \cdot \ell^{-1}$. The signal at $3.7 \delta$ was visible, but only as a weak band, after the instrument's sensitivity was enhanced by a factor of 10 (compare the $y$-axes of Figs. 3 and 4). This implies that ${ }^{1} \mathrm{H}$ 
Figure 4

${ }^{1} \mathrm{H} N \mathrm{NMR}$ spectrum of polyDADMAC at $0.1 \mathrm{mg} \cdot \ell^{-1}$

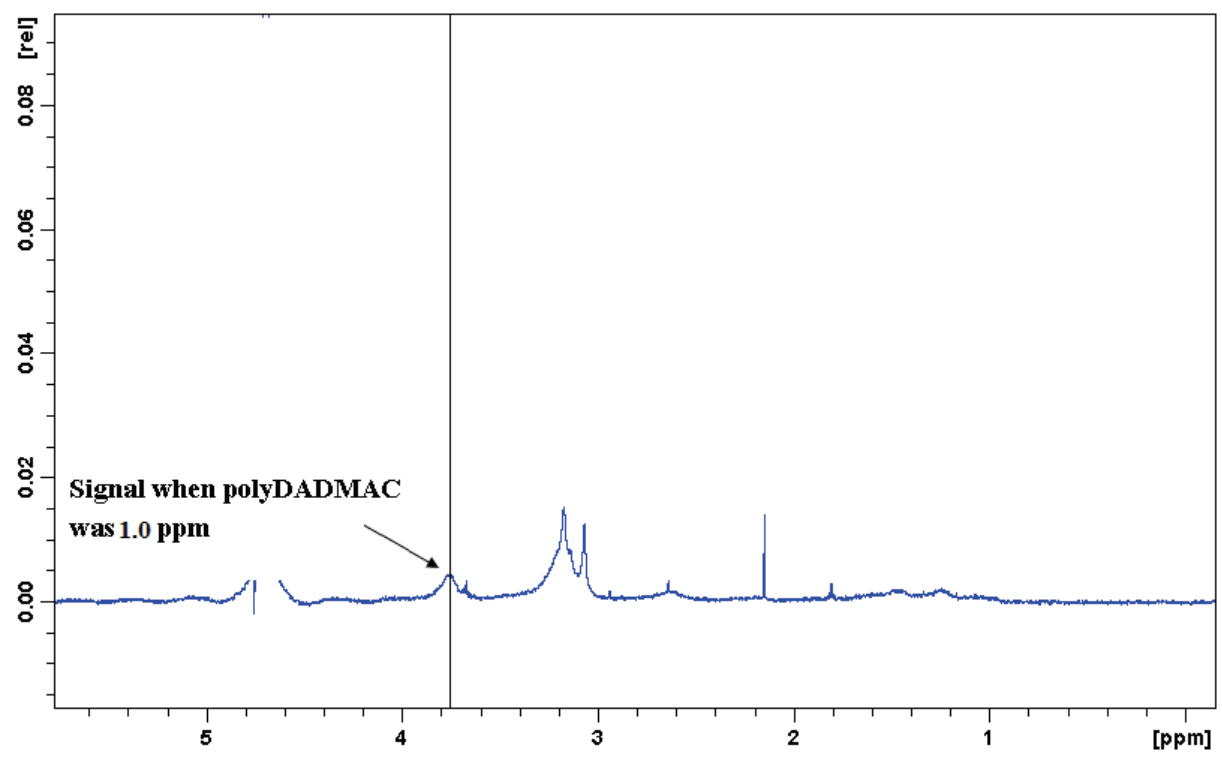

Figure 5

UV-Vis spectra of the polyDADMAC-dye ion pair: (A) UV region, and (B) Visible region; (i) indicates the lowest concentration, $0.4 \mathrm{mg} \cdot \ell^{-1}$, and (iv) the highest concentration, $1.0 \mathrm{mg} \cdot \ell^{-1}$, for the standards $0.4,0.6,0.8$ and $1.0 \mathrm{mg} \cdot \ell^{-1}$

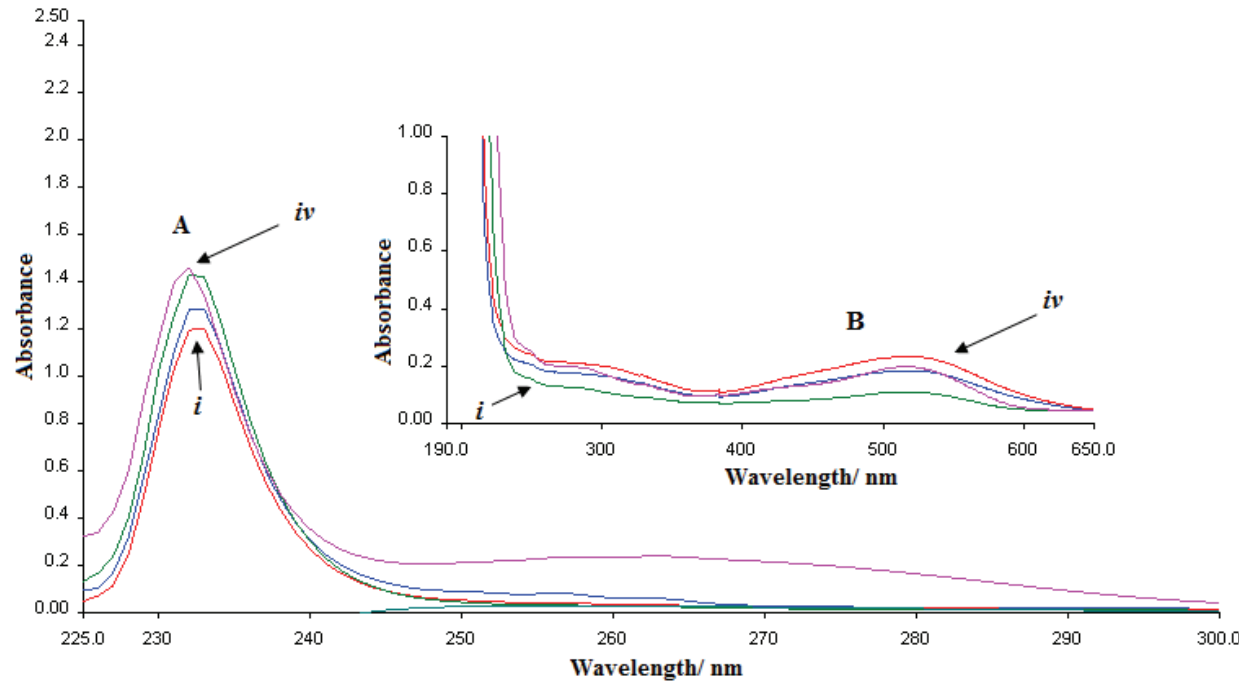

NMR is not a suitable technique for quantification of low concentrations of polyDADMAC in aqueous solution.

\section{UV-Vis characterisation}

In the preliminary experiment, to establish if absorption in the visible region obeyed the Beer-Lambert law, solutions with different concentrations $\left(0.4,0.6,0.8\right.$ and $1.0 \mathrm{mg} \cdot \ell^{-1}$ of polyDADMAC) of the ion pair were analysed by UV-Vis spectrophotometry (between 400 and $600 \mathrm{~nm}$ ). The resulting spectra are shown in Fig. 5.

It was observed that the polyDADMAC-dye ion pair has an absorption peak in the visible region (as shown in Fig. 5(B) inset) at a wavelength of $520 \mathrm{~nm}$. This agrees with the findings of other workers who analysed phenols (related organics) by spectrophotometric methods, after formation of derivatives with the same dye (Whitlock et. al., 1972). In addition, Oakes et. al (2001) reported similar observations of maximum absorbance at $520 \mathrm{~nm}$ for the oxidation of azo dyes in aqueous media. In this study, varying concentrations of standard solutions $\left(0.4,0.6,0.8\right.$ and $\left.1.0 \mathrm{mg} \cdot \ell^{-1}\right)$ showed a significant difference in absorbance values (obeying Beer-Lambert law) in the visible spectrum (at $520 \mathrm{~nm}$ ). We also observed that the ion pair gave significantly higher intensities in the UV region than those in the visible spectrum (compare the spectra of Fig. 5(A), $235 \mathrm{~nm}$ with Fig. 5(B), $520 \mathrm{~nm}$ ). The high intensities in the UV region could be attributed to the conjugation of the dye (Kotera et. al., 1955). Thus, in the UV region the Beer-Lambert law was obeyed up to $0.8 \mathrm{mg} \cdot \ell^{-1}$, and spectrophotometric determination of polyDADMAC was therefore carried out in this region.

The effect of $\mathrm{pH}$ on the wavelength of maximum absorbance $\left(\lambda_{\max }\right)$ was studied. Solutions of the ion pair were prepared at different $\mathrm{pH}$ values $(1.50-12.00)$. The results obtained (spectra not shown) revealed that $\mathrm{pH}$ has no significant effect on $\lambda_{\text {max }}$ at $205 \mathrm{~nm}$ and $230 \mathrm{~nm}$, for solutions prepared in 1,4-dioxane and DMF, respectively. This confirms observation by Al-Shihry (2005) that $\mathrm{pH}$ has no effect on the conjugation of the molecule. However, the effect of solvent type on $\lambda_{\text {m }}$ observed in our study was similar to observations reported by Dubas (2006). This solvatochromic effect was observed by Stamatovska and co-workers in 2006, in studies of the effect of solvents on electronic absorption spectra. They explained that the phenomenon was due to the free interaction of the chromophores in the molecules, whose absorption falls within a specific band arising from the delocalisation of the p-system, which spreads over the whole molecule. A study by Kotera 


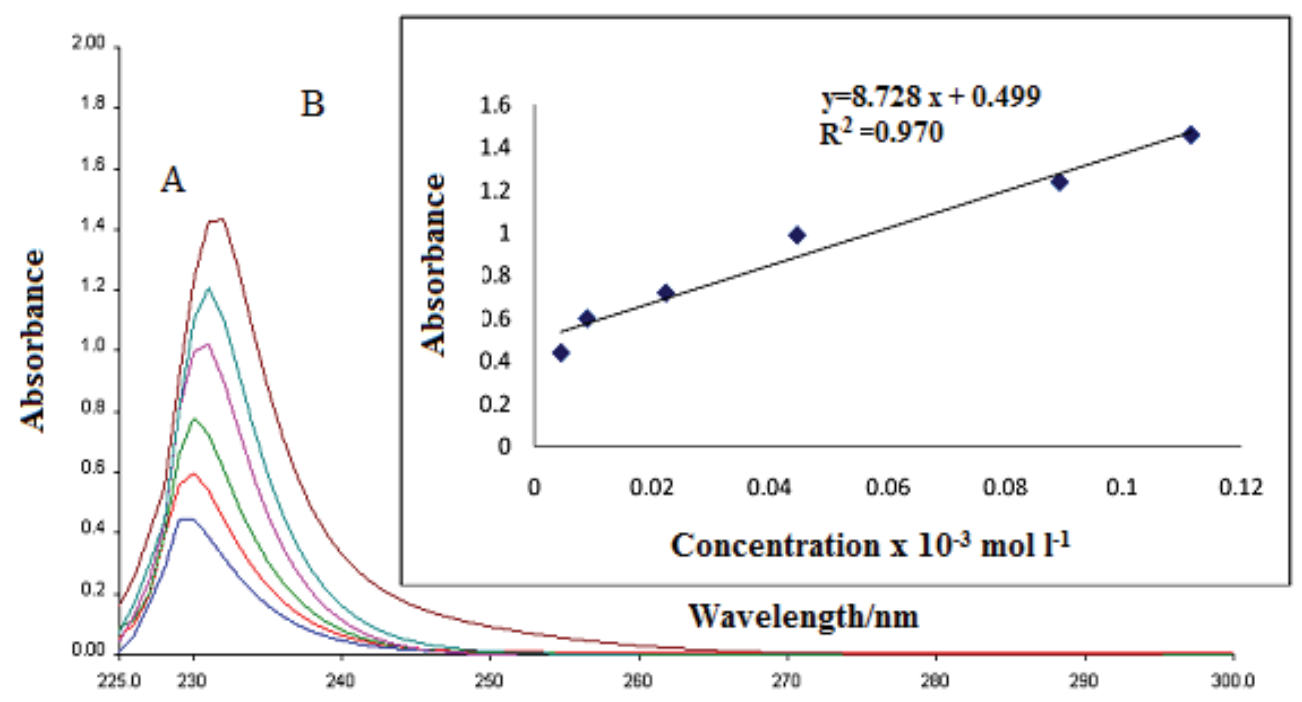

Figure 6

(A) Spectra of polyDADMAC-dye ion

pair dissolved in DMF, and $(B)$ calibration plot for determination of DADMAC, concentration range $1.95 \mathrm{x}$ $10^{-4}-4.88 \times 10^{-2} \mathrm{~mol} \cdot \ell^{-1}$ of the ion pair; $\lambda_{\max }=230 \mathrm{~nm}$; linear regression, $R^{2}=0.970 ;$ slope $=8728$ $\mathrm{mol}^{-1} \cdot \ell \cdot \mathrm{cm}^{-1}$

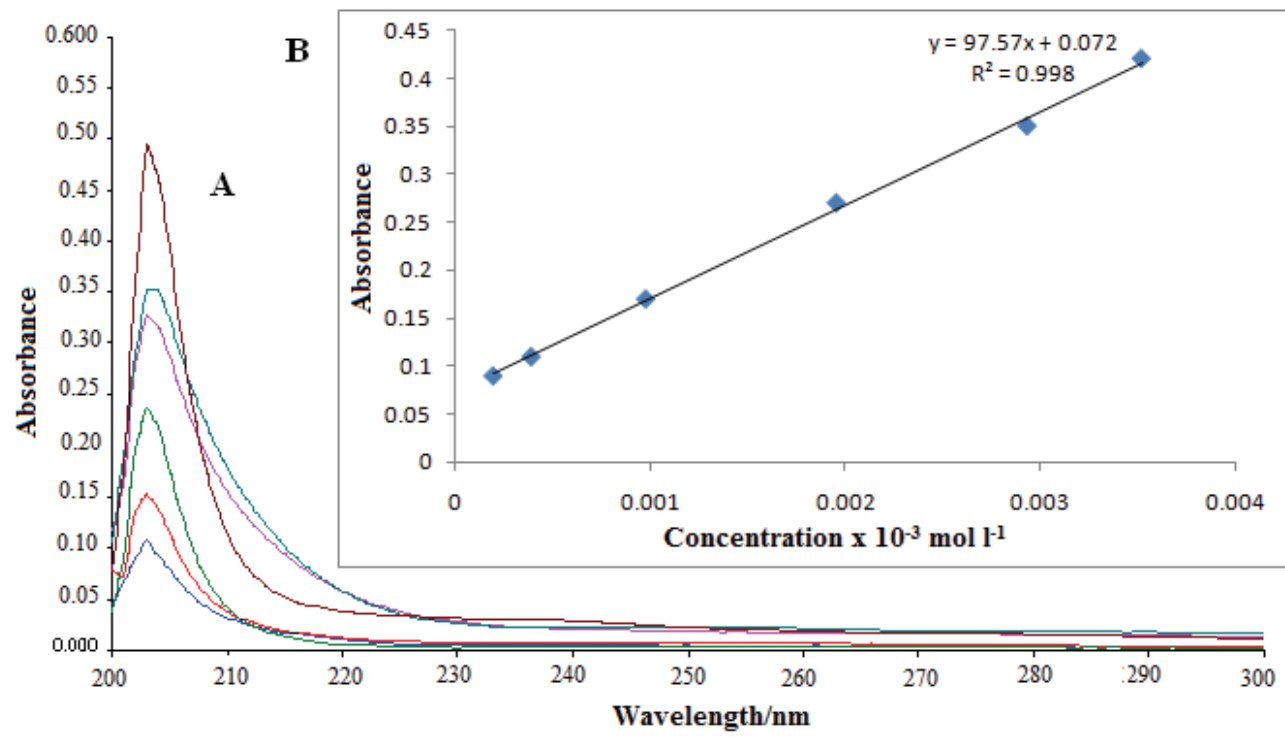

Figure 7

(A) Spectra of polyDADMAC-dye ion pair dissolved in 1,4-dioxane; and $(B)$ calibration plot or determination of DADMAC using concentration range $1.95 \times 10^{-4}-3.51 \times 10^{-3}$ $\mathrm{mol} \cdot \ell^{-1}$ of the ion pair; $\lambda_{\text {max }}=205 \mathrm{~nm}$; linear regression, $R^{2}=0.998$; slope $=9778 \mathrm{~mol}^{-1} \cdot \ell \cdot \mathrm{cm}^{-1}$

and co-workers (1955) reported that solvents contribute a shift in $\lambda_{\max }$ due to dipole-dipole moments in functional groups. Stamatovska et. al. (2006) also reported that the effects of solvent polarity and hydrogen bonding on the absorption spectra were interpreted by the linear solvation energy relationships (LSER) concept developed by Kamlet and Taft (Bekárek, 1983; Kamlet et. al., 1983).

\section{Calibration plots of polyDADMAC-dye ion pair by UV spectrophotometry}

A calibration curve for the determination of the polyDADMAC ion pair was prepared with standard solutions in the range 0.1-25.0 $\mathrm{mg} \cdot \ell^{-1}$ polyDADMAC (proportional to molar concentration range $6.18 \times 10^{-7}-1.55 \times 10^{-4} \mathrm{~mol} \cdot \ell^{-1}$ of DADMAC monomer, molar mass $\left.161.66 \mathrm{~g} \cdot \mathrm{mol}^{-1}\right)$. The dissociated units of polyDADMAC in water react with the dye to form ion-pair colloids with a molar mass of $511.99 \mathrm{~g} \cdot \mathrm{mol}^{-1}$ (De Gennes, 1979). On this basis, the resulting concentrations of the ion pair formed would be proportional to $1.95 \times 10^{-4}-4.88 \times 10^{-2} \mathrm{~mol} \cdot \ell^{-1}$. Figure 6(A) shows the various overlaid spectra for standard solutions of polyDADMAC prepared in DMF $(10 \mathrm{~m} \ell)$, showing the $\lambda_{\text {max }}$ at $230 \mathrm{~nm}$, while the inset (B) is the corresponding calibration plot with concentrations in $\mathrm{mol} \cdot \ell^{-1}$. Note that the molar absorptivity was calculated in $\mathrm{mol} \cdot \ell^{-1} \cdot \mathrm{cm}^{-1}$.

As shown in Fig. 6, the plot is linear with a correlation coefficient $\left(R^{2}\right)$ of 0.970 and a slope of $8728 \mathrm{~mol} \cdot \ell^{-1} \cdot \mathrm{cm}^{-1}$. Similar results were obtained by Al-Shihry (2005) for spectroscopic studies of inclusion complexes of (4-hydroxy1-napthylazo) benzene-sulphonic acid with cyclodextrin in aqueous solution, giving a molar absorption coefficient of 8756 $\mathrm{mol} \cdot \ell^{-1} \mathrm{~cm}^{-1}$ at $235 \mathrm{~nm}$. A second calibration for polyDADMAC standards prepared in 1,4-dioxane $(10 \mathrm{~m} \ell)$, showing $\lambda_{\text {max }}$ at 205 $\mathrm{nm}$, was obtained with concentrations ranging $0.1-1.8 \mathrm{mg} \cdot \ell^{-1}$ $\left(6.18 \times 10^{-7}\right.$ to $1.12 \times 10^{-5} \mathrm{~mol} \cdot \ell^{-1}$ DADMAC). The corresponding molar concentrations of the ion pair formed, based on the above argument, would be $1.95 \times 10^{-4}-3.51 \times 10^{-3} \mathrm{~mol} \cdot \ell^{-1}$. Figure 7(A) shows the various overlaid spectra of the standard solutions $\left(1.95 \times 10^{-4}-3.51 \times 10^{-3} \mathrm{~mol} \cdot \ell^{-1}\right)$, while insert $7(\mathrm{~B})$ is a linear calibration plot showing a correlation coefficient $\left(R^{2}\right)$ of 0.998 , intercept 0.089 and molar absorptivity of $9757 \mathrm{~mol} \cdot \ell^{-1} \mathrm{~cm}^{-1}$.

\section{Detection limit}

The limit of detection (DL) was obtained graphically from the full calibration curve (prepared in 1,4-dioxane at $\lambda_{\max }$ of 205 
$\mathrm{nm}$, with a range of $0.05-2.0 \mathrm{mg} \cdot \ell^{-1}$ of polyDADMAC which translates to $3.09 \times 10^{-7}-1.24 \times 10^{-5} \mathrm{~mol} \cdot \ell^{-1}$ of ion-pair). The calculated DL value was $0.07 \mathrm{mg} \cdot \ell^{-1}$, which is proportional to a molar concentration of $1.37 \times 10^{-7} \mathrm{~mol} \cdot \ell^{-1}$ for the ion pair. On the basis of the DL value, this method would be suitable for the determination of the flocculant, polyDADMAC, at trace levels (concentrations $<0.1 \mathrm{mg} \cdot \ell^{-1}$ ).

\section{Analysis of environmental water samples}

Water samples (collected from the Umgeni River in Durban) were treated with $0.045 \mathrm{mg} \cdot \ell^{-1}$ polyDADMAC and filtered. Each of the filtrates $(2 \ell)$ was spiked with 2 different concentrations of polyDADMAC $\left(100 \mathrm{~m} \ell\right.$ of $0.5 \mathrm{mg} \cdot \ell^{-1}$ and $\left.1.2 \mathrm{mg} \cdot \ell^{-1}\right)$ and labelled as S1 and S2, respectively. The purpose of spiking the sample with the standards was to obtain relatively high concentration levels of polyDADMAC, detectable by the UV-Vis spectrophotometer.

The spiked samples were treated using a similar procedure to the standard solutions. The ion-pair formed was then dissolved in $10 \mathrm{~m} \ell$ of 1,4-dioxane and the absorbance readings recorded. It was observed that water sample S1 (spiked with $0.5 \mathrm{mg} \cdot \ell^{-1}$ polyDADMAC) had an absorbance reading of 0.336 while S2 (spiked with $1.25 \mathrm{mg} \cdot \ell^{-1}$ polyDADMAC) gave a reading of 0.193 . Based on the amounts of polyDADMAC added to the water samples (after treatment and spiking), it is expected that the final concentrations would be $0.545 \mathrm{mg} \cdot \ell^{-1}$ and 1.245 $\mathrm{mg} \cdot \ell^{-1}$ for the $\mathrm{S} 1$ and $\mathrm{S} 2$ samples, respectively, assuming that no coagulation took place. The experimental values obtained with the UV-Vis method were $0.546 \mathrm{mg} \cdot \ell^{-1}$ and $1.245 \mathrm{mg} \cdot \ell^{-1}$ for $\mathrm{S} 1$ and S2, respectively, or $1.01 \times 10^{-6}$ or $2.43 \times 10^{-6} \mathrm{~mol} \cdot \ell^{-1}$, (based on a molar mass $511.99 \mathrm{~g} \cdot \mathrm{mol}^{-1}$ for the ion pair formed). The results show an average difference of $0.045 \mathrm{mg} \cdot \ell^{-1}$, which is not significantly different (based on ANOVA at $p=0.05$, $\mathrm{n}=8$ ) from the initial amount of $0.045 \mathrm{mg} \cdot \ell^{-1}$ used in the treatment. This indicates that the UV method is reasonably accurate for the determination of polyDADMAC at these concentration levels. The implication of these results is that when polyDADMAC is applied in the treatment of uncontaminated water (as is the case in our study), the final product may possibly contain the unreacted polycation. The latter is known to form compounds of health concern when reacting with chlorinated by-products (Park et. al., 2009).

\section{Conclusions}

Quantitative determination by ${ }^{1} \mathrm{H}$ NMR spectroscopy of residual polyDADMAC in treated water at trace levels $(<0.1$ $\left.\mathrm{mg} \cdot \ell^{-1}\right)$ was not possible due to the poor sensitivity of the method. The UV spectrophotometric technique showed better sensitivity (in terms of the detection limit) for the quantification of polyDADMAC. Formation of stable UV-active colloids of a polyDADMAC-dye ion pair and their subsequent solvation in DMF or 1,4-dioxane made determination of the flocculant residue possible. The colloid formation was due to the high affinity of polyDADMAC for negatively-charged/neutral particles of the (4-hydroxy-1-napthylazo) benzene-sulphonic acid dye. Thus, the reaction between the polyelectrolyte and the dye enabled this UV-inactive compound (polyDADMAC) to be analysed by the spectrophotometric technique. The effect of $\mathrm{pH}$ on $\lambda_{\max }$ for the polyDADMAC-dye complex was found to be insignificant for the two solvents systems studied. On the other hand, the nature of the solvent was found to play a significant role in determining the $\lambda_{\max }$ value. The solvent chosen was 1,4-dioxane, because of the low concentration range investigated (linear range $0.1-1.8 \mathrm{mg} \cdot \ell^{-1}$ ), which gave a detection limit of $0.07 \mathrm{mg} \cdot \ell^{-1}(70 \mathrm{ppb})$ of polyDADMAC, a value proportional to a molar concentration of $1.37 \times 10^{-7} \mathrm{~mol} \cdot \ell^{-1}$ of the ion pair. The developed method was found to be relatively easy for routine analysis, compared to the existing methods based on colloidal titration. The experimental results were found to be in close agreement with the expected values of the polyelectrolyte in the spiked water samples. The UV method developed in this study is suitable for trace analysis (concentrations $<0.1 \mathrm{mg} \cdot \ell^{-1}$ ). The advantage of the developed method is that the UV spectrophotometric technique is simple, fast and does not require specialised skills.

In addition, the method is applicable for detection of polyDADMAC in the presence of interfering species in treated wastewater. This is because of the selective formation of the ion-pair with the dye which results in gravimetric precipitation of the ion-pair complex that can subsequently be determined spectrophotometrically. This selectivity is based on the fact that other substances in the water will not react with the dye and hence will remain in solution. Moreover in the case of co-precipitation of the analyte with any other species present in water, absorption of the complex will not take place at the same wavelength, as demonstrated in this study.

\section{Acknowledgements}

IW Mwangi wishes to thank OPCW for financial support as well as his employer, Kenyatta University, for granting the study leave to undertake the $\mathrm{PhD}$ programme.

\section{References}

AL-SHIHRY SS (2005) Spectroscopic studies of inclusion complexes of 1-naphthol-4-sulfonate with cyclodextrin in aqueous solution. Spectrochim. Acta. Part A $612439-2443$.

ASSEM Y, GREINER A and AGARWAL S (2007) Microwaveassisted controlled ring-closing cyclopolymerization of diallyldimethylammonium chloride via the RAFT process. Macromolecules 28 1923-1928.

BECKER NSC, BENNETT DM, BOLTO BA, DIXON DR, ELDRIDGE RJ, LE NP and RYE CS (2004) Detection of polyelectrolytes at trace levels in water by fluorescent tagging. React. Funct. Polym. $60183-193$.

BEKÁREK V (1983) Improvement of the applicability of Taft-Kamlet solvent polarity parameters to chemical reactivity. J. Chem. Soc. Perkin Trans. 2 1293-1296.

COATES J (2000) Interpretation of infrared spectra, a practical approach. Encyclopedia of Analytical Chemistry. John Wiley \& Sons Ltd, Chichester. 10815-10837.

GENNES PG de (1979) Scaling Concepts in Polymer Physics ( $1^{\text {st }}$ edn.). Cornell University Press, New York.

DUBAS ST, CHULARAT IC and POTIYARAJ CP (2006) Optical alcohol sensor based on dye-chitosan polyelectrolyte multilayers. Sensor Actuator B 113 370-375.

FAUST AD and ALY OM (1983) Chemistry of Water Treatment. Butterworths, Boston.

HORITA K, WANG GF and SATAKE M (1997) Column preconcentration analysis-spectrophotometric determination of nitrate and nitrite by a diazotization-coupling reaction. Analyst 122 1569-1574.

JOHN W, BUCKLEY CA, JACOBS EP and SANDERSON DR (2002) Analysis of polydadmac by off-line membrane filtration gel permeation chromatography. URL: www.ewisa.co.za/literature/ files/404\%20John.pdf (Accessed 6 February 2011).

KAMLET MJ, ABBOUD LM, ABRAHAM MH and TAFT RW (1983) Linear solvation energy relationships, 23: A comprehensive collection of the solvatochromic parameters, $\pi^{*}, \alpha, \beta$, and some 
methods for simplifying the generalized solvatochromic equation. J. Org. Chem. 48 2877-2887.

KHAZAEI A, SOUDBAR D, SADRI M and MOHAGHEGH SMS (2007) Synthesis and characterization of poly(8-hydroxyquinolinep-styrene sulphonate) and study of its controlled release behaviour. Iran. Polym. J. 16 (5) 309-317.

KOTERA A, SHIBATA S and SONE K (1955) The dipole moments and near ultraviolet spectra of some compounds containing the CONH groups. J. Am. Chem. Soc. 77 6183-6186.

KÜGLER R, BOULOUSSA O and RONDELEZ F (2005) Evidence of a charge-density threshold for optimum efficiency of biocidal cationic surfaces. Microbiology 151 1341-1348.

LANCASTER JE, BACCEI L and PANZER HP (1976) Synthesis and aqueous solution behavior of novel ph responsive, zwitterionic cyclocopolymers J. Polym. Sci Part C Polym. Lett. 14 549-554.

MAJAM S, JONNALAGADDA SB and THOMPSON P (2004) Development of analytical methods for organic polymer determination used in water treatment. Proc. Environmental Science and Technology - Water institute of Southern African biannual conference, 6 May 2004, Cape Town, South Africa. 62-67.

MOCCHIUTTI P and ZANUTTINI MA (2007) Key considerations in the determination of polyelectrolyte concentration by the colloidal titration method. Bioresources 2 (3) 399-407.

MUKAMEL S (2000) Multidimensional fentosecond correlation spectroscopies of electronic and vibrational excitations. Ann. Rev. Phys. Chem. 51691.

OAKES J, GRATTON P, WILKES I and GORDON-SMITH T (2001) Kinetic and spectroscopic study of heterogeneous oxidation of azo dyes using hypochlorite. Color Technol. 117 76-82.

PARAZAK DP, BURKHARDT CW and McCARTHY KJ (1987) Determination of low levels of cationic polyelectrolytes in water. Anal. Chem. 59 1444-1445.

PARK SH, WEI S, MIZAIKOFF B, TAYLOR AE, FAVERO C and HUANG C (2009) Degradation of amine-based water treatment polymers during chloramination as $\mathrm{N}$-nitrosodimethylamine (NDMA) precursors. Environ. Sci. Technol. 43 1360-1366.

SAKAI T (2001) Stepwise determination of quatenary ammonium salts and aromatic amines in pharmaceuticals by ion pair titration. Analytical Sci. 17 1379-1382.
SAVEYNA H, PIETER MS, DENTELC HSK, MARTINSB JC and VAN DER MEERENA P (2008) Quantification of hydrolytic charge loss of DMAEA-Q-based polyelectrolytes by proton NMR spectroscopy and implications for colloid titration. Water Res. $\mathbf{4 2}$ 2718-2728.

SCHOUTISSEN HAJ (1933) The character of the diazonium group and a new method of preparing mixed disazo dyestuffs. J. Am. Chem. Soc. 55 (11) 4541-4545.

STAMATOVSKA VD, DIMOVA V and COLANCESKA-RAGENOVIK K (2006) Solvent effect on electronic absorption spectraof some n-aryl substituted dodekanamides. Bull. Chem. Technol. Macedonia 25 (1) 9-16.

TILLER J, LIAO C, LEWIS K and KLIBANOV A (2001) Designing surfaces that kill bacteria on contact. Proc. Natl. Acad. Sci. USA. 98 5981-5985.

WANGA CN, METCALFEA LD, DONKERBROEKB JJ and OSIJNB AHM (1989) Potentiometric titration of long chain quaternary ammonium compounds using sodium tetraphenyl borate. J. Am. Oil Chem. Soc. 66 (2) 1831-1833.

WHITLOCK LR, SIGGIA IS and SMOLA JE (1972) Spectrophotometric analysis of phenols and of sulfonates by formation of an azo dye. Anal. Chem. 44 (3) 532-536.

XAMENA FXL, AREÁN CO, SPERA S, MERLO E and ZECCHINA A (2004) Formaldehyde oligomerization on silicalite: an FTIR and NMR study. Catal. Lett. 95 (1-2) 221-224.

XIA L, ENGEL K, ZHOU M and WANG J (2007) Membrane localization and $\mathrm{pH}$-dependent transport of a newly cloned organic cation transporter (PMAT) in kidney cells. Am. J. Renal Physiol. $292682-690$.

YANG TCK, LIN S, GUO W, CHUANG T and WANG S (1996) In-situ studies of the photodegradation of a dye adsorbed on $\mathrm{TiO}_{2}$ particles by the drifts. Phys. Chem. $100683-688$.

ZANDER N, LEADORE J and ORLICKI JA (2008) Charge density quantification and antimicrobial efficacy. ARL-TR-4530 August 2008. Army Research Laboratory, Aberdeen. URL: http://www. dtic.mil/cgi-bin/GetTRDoc?Location=U2\&doc=GetTRDoc. pdf\&AD=ADA487526. 